\title{
EVALUASI PELAYANAN PROGRAM JAMPERSAL : TINJAUAN DIMENSI MUTU PELAYANAN JAMPERSAL
}

\author{
Leli Mulyati, Chandra Buana, Putri Janiarti \\ Poltekkes Bengkulu Prodi Keperawatan Curup, Jl. Sapta Marga.95 Curup
}

\begin{abstract}
Knowing the factor fo pregnant women to choose jampersal service health center in the region of Curup Year 1012.

The research is using descriptive design. The sampling using purposive sampling. With 67 people and count using univariant.

From this study it can be seen from the technical competence almost half of respondents (48.2\%) responded strongly agree, Access to almost all respondents $(52.23 \%)$ responded agree. The effectiveness of almost all respondents $(51.23 \%)$ responded agree. Continuity of care almost all respondents $(51.73 \%)$ responded agree, security is almost all respondents $(51.23 \%)$ responded agree. Human interpersonal almost all respondents $(52.76 \%)$ responded agree, and the comfort of pleasure almost all respondents $(50.23 \%)$ responded agree. Based the conclusion, of the 67 respondents can be concluded the vast majority of respondents $(52.23 \%)$ said quality of care at health centers is good and almost Curup majority of respondents $(47.76 \%)$ stated quality of care at health centers Curup not good.
\end{abstract}

Keywords: Pregnancy, Jampersal Service

Abstrak : Tujuan : Mengetahui faktor wanita hamil untuk memilih layanan Jampersal Puskesmas di wilayah Curup Tahun 1012.

Penelitian ini menggunakan desain deskriptif. Pengambilan sampel menggunakan purposive sampling . Dengan 67 orang dan jumlah menggunakan univariat.

Penelitian ini dapat dilihat dari kompetensi teknis hampir separuh responden $(48,2 \%)$ menjawab sangat setuju, akses ke hampir semua responden $(52,23 \%)$ menjawab setuju. Efektivitas hampir semua responden $(51,23 \%)$ menjawab setuju. Kontinuitas perawatan hampir semua responden $(51,73 \%)$ menjawab setuju, keamanan hampir semua responden $(51,23 \%)$ menjawab setuju. Manusia antarpribadi hampir semua responden $(52,76 \%)$ menjawab setuju, dan kenyamanan kesenangan hampir semua responden ( $50,23 \%)$ menjawab setuju. Berdasarkan kesimpulan, dari 67 responden dapat disimpulkan sebagian besar responden (52,23\%) mengatakan kualitas pelayanan di puskesmas baik dan sebagian hampir Curup responden (47.76\%) menyatakan kualitas pelayanan di puskesmas tidak Curup baik.

Kata Kunci : Kehamilan, Layanan Jampersal

Angka Kematian Bayi (AKB ) dan Angka Kematian Ibu ( AKI ) di Indonesia masih cukup tinggi di bandingkan dengan negara ASEAN lainnya. Menurut data survei Demografi Kesehatan Indonesia ( SDKI ) tahun 2007, AKI dari 228 per 100.000 kelahiran hidup (KH), AKB 34 per 1000 kelahiran hidup, Angka Kematian Neonatus (AKN) 19 per 1000 kelahiran hidup. Dalam rangka mempercepat pencapaian tujuan pembangunan kesehatan serta Millennium Development Goals (MDG's), maka mulai tahun 2011 ini pemerintah meluncurkan kebijakan Jaminan Persalinan (Jampersal). Jaminan ini khusus ditujukan kepada ibu-ibu yang menjalani proses
persalinan.Target RPJMN Tahun 20102014 mengamanatkan agar AKI dapat diturunkan menjadi 118 per 100.000 kelahiran hidup pada tahun 2014. Selain itu, kesepakatan lobal (MDGs) menargetkan AKI di Indonesia dapat diturunkan menjadi 102 per 100.000 kelahiran hidup pada tahun 2015.

Menurut hasil Riskesdas 2010, persalinan oleh tenaga kesehatan pada kelompok sasaran miskin (Quintil 1) baru mencapai sekitar $69,3 \%$. Sedangkan persalinan yang dilakukan oleh tenaga kesehatan di fasilitas kesehatan baru mencapai $55,4 \%$. Keadaan seperti ini banyak terjadi disebabkan kendala biaya sehingga di- 
perlukan kebijakan terobosan untuk meningkatkan persalinan yang ditolong tenaga kesehatan di fasilitas kesehatan.

Data dari Dinas Kesehatan data Kabupaten Rejang Lebong Tahun 2011 dari 21 Kabupaten yang menjadi sasaran yaitu Ibu Hamil sebanyak 4.877 orang, ibu bersalin sebanyak 4.655 orang, Ibu Nifas sebanyak 4.655 orang dan Bayi sebanyak 4.655 orang. Hasil rekapitulasi data laporan kesertaan dan pemanfaatan layanan Jampersal, Puskesmas Curup merupakan salah satu Puskesmas yang telah menjalankan program Jampersal periode 2011. Jumlah Keseluruhan yang terdata di Wilayah Kerja Puskesmas CurupTahun 2011 yaitu Jumlah Ibu Hamil 702 orang, Ibu Bersalin 670 dan Ibu Nifas 670 Orang. Dari 11 Kelurahan dengan jumlah penduduk sebanyak 35.433 orang dan KK (Kepala Keluarga) sebanyak 8.729 orang. Jjumlah kunjungan pemeriksaan yang terdaftar di layanan Jampersal yaitu Ibu Hamil 207 orang, Ibu Besalin 190 orang yang bersalin di rujuk ke RSUD (Rumah Sakit Umum Daerah) 17 orang dan yang Nifas 207 orang. Jumlah semua yang mengikuti Jampersal 207 orang dari keseluruhan 702 orang. Dari uraian di atas dapat dilihat bahwa masih rendahnya angka pencapaian

program jampersal di PKM Curup kabupaten Rejang Lebong tahun 2012. Tujuan Penelitian ini adalah untuk mengetahui bagaimanakah pelaksanaan program jampersal di wilayah kerja Puskesmas $\mathrm{Cu}$ rup Tahun 2012.

\section{BAHAN DAN CARA KERJA}

Desain penelitian yang digunakan adalah deskriptif dengan pendeketan Cross Sectional. Variable dalam penelitian adalah faktor-faktor yang meliputi dimensi mutu pelayanan kesehatan. Populasi dalam penelitian ini adalah jumlah keseluruhan ibu hamil yang terdaftar mengikuti kunjungan pemeriksaan di Puskesmas Curup Tahun 2012 sebanyak 207 Orang.

Pengambilan sampel menggunakan tehnik sampel "Purposive Sampling". Pengumpulan Data menggunakan data Primer Pengumpulan Data : Pengumpulan data dilakukan dengan menggunakan kuisioner sebanyak 21 pertanyaan. Pengolahan dan analisis data menggunakan analisis univariat.

\section{HASIL}

\section{Analisa Univariat}

Tabel 1. Distribusi Frekuensi Gambaran Responden Tentang Dimensi Mutu Pelayanan Di Puskesmas Curup Tahun 2012

\begin{tabular}{|c|c|c|c|c|}
\hline \multirow{3}{*}{ Dimensi Mutu Pelayanan } & \multicolumn{4}{|c|}{ Pernyataan } \\
\hline & \multicolumn{2}{|c|}{ Baik } & \multicolumn{2}{|c|}{ Tidak Baik } \\
\hline & $\mathrm{N}$ & $\%$ & $\mathrm{~N}$ & $\%$ \\
\hline Tingkat Kompetensi Teknis & 30 & 44,78 & 37 & 55,22 \\
\hline Akses Terhadap Layanan & 34 & 50,75 & 33 & 49,25 \\
\hline Evektifitas & 32 & 47,76 & 35 & 52,24 \\
\hline Kelangsungan Pelayanan & 33 & 49,25 & 34 & 50,75 \\
\hline Keamanan & 34 & 50,75 & 33 & 49,25 \\
\hline Hubungan Antar Manusia & 32 & 47,76 & 35 & 52,24 \\
\hline Kenyamanan, Kenikmatan & 33 & 49,25 & 34 & 50,75 \\
\hline
\end{tabular}

Berdasarkan Tabel 1. dapat dilihat bahwa dari Kompetensi teknis sebagian besar dari responden $(55,22 \%)$ menjawab tidak baik, Akses terhadap layanan sebagian besar dari responden $(50,75 \%)$ menjawab baik, Efektifitas sebagian besar dari responden $(52,24 \%)$ menjawab tidak baik, Kelangsungan pelayanan sebagian besar dari responden $(50,75 \%)$ menjawab tidak baik, Keamanan sebagian besar dari responden $(50,75 \%)$ menjawab baik, Hubungan Antar Manusia sebagian besar dari responden $(52,24 \%)$ menjawab tidak baik, dan dari kenyamanan, kenikmatan sebagian besar dari responden $(50,75 \%)$ menjawab tidak baik. 
Tabel 2. Distribusi Frekuensi Berdasarkan Mutu Pelayanan Di Puskesmas Curup Tahun 2012

\begin{tabular}{ccc}
\hline Mutu Pelayanan & Frekuensi & Persentase (\%) \\
\hline Baik & 35 & $52,24 \%$ \\
Tidak Baik & 32 & $47,76 \%$ \\
Total & 67 & $100 \%$ \\
\hline
\end{tabular}

Berdasarkan Tabel 2 dapat dilihat bahwa sebagian besar responden $(52,24 \%)$ menjawab mutu pelayanan di puskesmas curup adalah baik.

\section{PEMBAHASAN}

Berdasarkan hasil penelitian di peroleh bahwa dari pernyataan 67 orang dari Kompetensi teknis sebagian besar dari responden $(55,22 \%)$ menjawab tidak baik, Akses terhadap layanan sebagian besar dari responden $(50,75 \%)$ menjawab baik, Efektivitas sebagian besar dari responden $(52,24 \%)$ menjawab tidak baik, Kelangsungan pelayanan sebagian besar dari responden $(50,75 \%)$ menjawab tidak baik, Keamanan sebagian besar dari responden (50,75\%) menjawab baik, Hubungan Antar Manusia sebagian besar dari responden $(52,24 \%)$ menjawab tidak baik, dan dari kenyamanan, kenikmatan sebagian besar dari responden $(50,75 \%)$ menjawab tidak baik.

Berdasarkan dimensi mutu pelayanan dapat di simpulkan bahwa tingkat kopetensi teknis tidak baik di terima masyarakat, akses terhadap layanan baik di terima masyarakat, efektifitas tidak baik di terima masyarakat, kelangsungan layanan tidak baik di terima masyarakat, keamanan baik di terima masyarakat, hubungan antar manusia tidak baik di terima masyarakat dan kenyamanan, kenikmatan tidak baik di terima masyarakat.

Berdasarkan hasil kesimpulan, dari 67 responden dapat di simpulkan sebagian besar dari responden $(52,24 \%)$ menyatakan mutu pelayanan di puskesmas curup adalah baik dan Hampir sebagian dari responden $(47,76 \%)$ menyatakan mutu pelayanan di puskesmas curup tidak baik.
Dengan demikian program Jampersal ini baik di terima oleh masyarakat khususnya ditujukan kepada ibu-ibu yang menjalani proses persalinan. Target Tahun 2010-2014 mengamanatkan agar AKI dapat diturunkan menjadi 118 per 100.000 kelahiran hidup pada tahun 2014. Selain itu, kesepakatan lobal (MDGs) menargetkan AKI di Indonesia dapat diturunkan menjadi 102 per 100.000 kelahiran hidup pada tahun 2015 (DepKes RI, 2010).

\section{KESIMPULAN}

Tingkat Kompetensi Teknik sebagian besar dari responden menyatakan tidak baik. Akses terhadap layanan sebagian besar dari responden menyatakan baik. Efektivitas sebagian basar dari responden menyatakan tidak baik. Kelangsungan pelayanan sebagian besar dari responden menyatakan tidak baik. Keamanan sebagian besar dari responden menyatakan baik. Hubungan Antar Manusia sebagian besar dari responden menyatakan tidak baik. kenyamanan, kenikmatan sebagian besar dari responden menyatakan tidak baik. Maka dapat di simpulkan Sebagian besar responden menyatakan bahwa mutu pelayanan jampersal di Puskesmas Curup tahun 2012 adalah baik di terima masyarakat.

Saran bagi Dinas Kesehatan Rejang Lebong diharapkan dapat memberi informasi dan masukan bagi perencana program, khususnya Jampersal. Bagi Puskesmas Curup, diharapkan untuk dapat mempertahankan dan meningkatkan mutu pelayanan terutama pada program Jampersal dan menjamin pelayanan tetap standar. Bagi Responden, diharapkan hasil penelitian ini menjadi dasar dan motivasi para ibu-ibu hamil yang banar-benar tidak memiliki biaya untuk mengikuti proses persalinan dengan normal sehingga mereka dapat memanfaatkan pelayanan Jampersal dengan baik. 


\section{DAFTAR RUJUKAN}

Arikunto.(2007).Prosedur Penelitian Suatu Pendekatan Praktek. Edisi V . Rhineka Cipta : Jakarta

Aziz, A. (2003). Riset Keperawatan Dan Teknik Penulisan Ilmiah. Jakarta : Salemba Medika

BPS (2007). Tingkat Ekonomi Keluarga. Diakses 3 maret 2011. Http://www.BPS.com.

Departemen Kesehatan Republik Indonesia( 2007). Sehat menurut WHO. Jakarta

Dinas Kesehata Rejang Lebong, Rejang Lebong Tahun 2011-2012. RejangLebong.

Endang, R. (2011). Petunjuk Teknis Jaminan Persalinan. Jakarta : MenKes RI.

Hidayat. 2007, Metode Penelitian Keperawatan dan Teknik Analisa Data, Edisi 1. Jakarta :Salemba Medika.
Label, Varay (2008) Makalah tenteng pengetahuan. Http://.phyciantricnursing weblog. Com

Mulyono. 2011, Tujuan Dari Jampersal.Http://Jampersal. Com

MenKes. 2011, Peraturan Kementeri Kesehatan Republik Indonesia Nomor 631. Jakarta :MenKes RI.

Notoatmojo, S. (2003). Metodelogi Penelitian Kesehatan. Jakarta: Rineka Cipta.

Puskesmas Curup. 2011 Laporan tahunan data kunjungan ibu hamil yang mengikuti jampersal

Wijono, D (2000). Manajemen mutu pelayanan kesehatan. Surabaya : Air langga University press 